\title{
IMPLIKATUR YANG MENIMBULKAN HUMOR DALAM SERIAL ROKU NIN NO OKUSAN OLEH SHIMURA KEN
}

\author{
Muhaimin \\ 312201300475@mhs.dinus.ac.id. \\ Universitas Dian Nuswantoro
}

\begin{abstract}
The purpose of this study was to describe the implicature of conversation that arise as the result of the violation of Grice's cooperative principle. The result showed that the implicature of conversation that exist in those speeches had been preeceded by violation of 4 maxims. There are implicature of conversation which are; apology, threat, denial, sneer, order, rebuke, emphasize, change of subject, intimidate, influence, and rejection. Based on the violation cooperative principle, the were conversational implicature which gave humor effects. Implicature of conversation which gave humor effects to the audience are : (1) Implicature which is a representation of an unexpected situation or something contrary. (2) Implicature which has potential, soften, mistreat, bother, cornered the speaker or spoken partner. (3) Implicature whis is a representation of unwanted condition, rejection, disagreement, compulsion, anger, and resistance. Implicature used as a medium of humor from the speaker to the audience signed by laughter of the audience, so that the purpose of humor program could be delivered which is to entertain people.
\end{abstract}

Keywords: speech act, cooperative principle, implicature, humor

Manusia merupakan mahluk sosial, yaitu makhluk yang membutuhkan orang lain dan bersosialisasi dengan lingkungan sosialnya. Agar dapat bersosialisasi dengan lancar dan dapat berkomunikasi dengan baik, maka dibutuhkan bahasa. Menurut Wibowo (2001:28) bahasa adalah sistem simbol bunyi yang bermakna dan berartikulasi (dihasilkan oleh alat ucap) yang bersifat arbitrer dan konvensional, yang dipakai sebagai alat berkomunikasi oleh sekelompok manusia untuk melahirkan perasaan dan pikiran.

Menurut Charles Morris (1938:101), semiotik (studi tentang makna) dibagi menjadi 3 cabang yaitu sintaksis, semantik, dan prakmatik. Sintaksis mempelajari tentang hubungan antara tanda-tanda dalam struktur formal. Semantik mempelajari tentang hubungan antara tanda dan hal-hal yang dapat dilihat (makna). Pragmatik mempelajari tentang mengkaji hubungan antara tanda dengan penafsiran (dalam Saifudin, 2005). Implikatur merupakan cabang ilmu dalam pragmatik. Implikatur 
berasal dari bahasa latin Implicare yang berarti melipat. Hal ini dijelaskan oleh Mey dalam Nadar (2009:60) bahwa untuk mengetahui tentang apa yang dilipat harus dengan cara membukanya. Dengan kata lain implikatur dapat dikatakan sebagai sesuatu yang terlipat. Implikatur dapat diartikan sebagaimana tambahan yang disampaikan penutur yang terkadang tidak terdapat pada tuturan itu sendiri. Sebuah tuturan dapat mengimplikasikan sesuatu yang bukan merupakan bagian dari tuturan tersebut. Sesuatu yang tersirat atau tidak bisa disampaikan secara langsung tersebut berpotensi menimbulkan kegagalan dalam berkomunikasi atau membingungkan mitra tuturnya. Sehingga menyebabkan komunikasi tidak berjalan dengan lancar. Implikatur yang ada dalam sebuah percakapan sering menimbulkan persepsi makna yang berbeda tergantung pada interpretasi mitra tuturnya. Humor yang disajikan dalam bentuk monolog maupun dialog yang berupa tuturan terdapat banyak sekali implikatur percakapan yang disampaikan secara tidak langsung yang dapat membuat tertawa para penonton. Implikatur yang terdapat pada acara-acara komedi, humor, atau cerita-cerita lucu dll, sering menimbulkan efek humor yang ditandai dengan suara tawa penonton.

Setiap orang pasti memiliki selera humor. Ada yang senang memendamnya karena malu, ada juga yang berani mengekspresikannya. Secara umum, humor adalah segala rangsangan mental yang secara spontan menimbulkan senyum dan tawa para penikmatnya. Humor juga dapat didefinisikan sebagai cerita yang menggelitik dan membuat tertawa pendengar atau pembaca yang mengerti maksud humor tersebut. Humor juga disebutkan sebagai sebagai sesuatu, baik verbal maupun nonverbal yang dapat menyebabkan orang tertawa atau sebuah efek kejut yang menimbulkan kelucuan (Saifudin A., dkk., 2019) Dalam Ensiklopedia Indonesia (1982), seperti yang dinyatakan oleh Setiawan dalam Ariefandi (1990:22), humor itu kualitas untuk menghimbau rasa geli atau lucu, karena keganjilannya atau ketidakpantasannya yang menggelikan, paduan antara rasa kelucuan yang halus di dalam diri manusia dan kesadaran hidup yang iba dengan sikap simpatik.

Dalam humor dibutuhkan kecerdasan kedua belah pihak, yaitu penutur dan mitra tutur. Penutur dituntut agar bisa menempatkan humornya pada waktu yang tepat, sebab apabila waktunya tidak tepat, humor tersebut dapat menjadi tidak lucu bahkan juga bisa 
Muhaimin, Implikatur yang Menimbulkan Humor dalam Serial Roku Nin no Okusan oleh Shimura Ken

menyakiti pihak lain. Selain itu, mitra tutur juga dituntut agar bisa bersikap dewasa dalam menanggapi sebuah humor, karena bagaimanapun tajamnya kritikan dalam sebuah humor, humor tetaplah humor.

Acara komedi Shimura Ken merupakan acara komedi yang sangat terkenal di Jepang. Acara komedi ini dimotori oleh seorang pelawak Jepang yang sangat terkenal yaitu Yasunori Shimura lahir pada 20 Febuary 1950 di Higashimurayama, Tokyo. Jepang. (Wikipedia, Yasunori Shimura). Acara komedi ini menampilkan hal-hal seperti: kritik sosial, politik, Kebudayaan dan lain-lain. Dalam acara ini Yasunori Shimura sering berkolaborarasi dengan berbagai aktor terkenal di Jepang. Seperti pada acara komedi seri Rokunin No Okusan ini, Ia berkolaborasi dengan: Kakigawa Hanako, Yuuka, Kondou Haruna, Nanao, Matsuko, dan Shibata Rie. Kelucuan dalam acara komedi terletak pada sikap tiap-tiap tokoh yang terkesan lucu, aneh, dan unik, yang dituangkan dalam bentuk gerakan maupun tuturan tokoh dalam berkomunikasi. Salah satu keunikan yang dimiliki dari acara humor yaitu bentukbentuk tuturan yang melanggar prinsip kerjasama dan mengandung implikatur percakapan yang selanjutnya implikatur percakapan tersebut dapat memberikan efek humor. Penulis skrip selaku penutur sengaja menuliskan tuturan-tuturan yang melanggar prinsip kerjasama yang mengandung implikatur percakapan untuk menciptakan efek lucu ketika tuturan tersebut didengar oleh penonton sebagai mitra tutur. Berdasarkan latar belakang tersebut Penulis mengambil penelitian yang berjudul implikatur percakapan yang menimbulkan efek humor kepada penonton dalam acara komedi Jepang Shimura Ken seri Rokunin no Okusan.

\section{KAJIAN TEORETIS}

\section{Pragmatik}

Menurut Levinson (1983: 9) "Pragmatic is the study of those relations between language and context that are grammaticalized, or encoded in the structure of a language." Pragmatik sebagai studi bahasa yang mempelajari relasi bahasa dengan konteksnya. Pengertian/pemahaman bahasa menunjuk kepada fakta bahwa untuk 
mengerti suatu ungkapan/ujaran bahasa diperlukan juga pengetahuan di luar makna kata dan hubungan tata bahasanya, yakni hubungannya dengan konteks pemakaiannya.

Konteks itu sendiri menurut Saifudin adalah kerangka konseptual tentang segala sesuatu yang dijadikan referensi dalam bertutur ataupun memahami maksud tuturan (2018). Kontekslah sebenarnya yang memberikan arti atau makna dalam percakapan. Ia berada dalam pikiran manusia yang diperoleh melalui belajar atau pengalaman hidupnya.

\section{Maksim Percakapan}

Grice (1991:309) menyatakan bahwa percakapan akan mengarah pada penyamaan unsur-unsur pada transaksi kerjasama yang semula berbeda. Penyamaan tersebut dilakukan dengan jalan: (1) menyamakan jangka tujuan pendek, meskipun tujuan akhirnya berbeda atau bahkan bertentangan, (2) menyatukan sumbangan partisipasi sehingga penutur dan mitra tutur saling membutuhkan, dan (3) mengusahan agar penutur dan mitra tutur mempunyai pengertian bahwa transaksi berlangsung dengan suatu pola tertentu yang cocok, kecuali bila bermaksud hendak mengakhiri kerjasama. Dalam rangka memenuhi keperluan tersebut, Grice menyatakan teori tentang aturan percakapan atau maksim yang dipandang sebagai prinsip atau dasar kerjasama. Prinsip kerjasama tersebut yakni berikanlah sumbangan Anda pada percakapan sebagaimana yang diperlukan sesuai dengan tujuan atau arah pertukaran pembicaraan yang Anda terlibat di dalamnya (Grice 1975:45). Prinsip tersebut mengharapkan para penutur untuk menyampaikan ujarannya sesuai dengan konteks terjadinya peristiwa tutur, tujuan tutur dan giliran tutur yang ada. Prinsip kerjasama tersebut, ditopang oleh maksim-maksim percakapan (maxim 4 of conversation), yaitu: maksim kuantitas, maksim kualitas, maksim relevansi, dan maksim cara.

\section{Maksim Kuantitas (The Maxim of Quantity)}

Di dalam maksim kuantitas, seorang penutur diharapkan dapat memberikan informasi yang cukup, relatif memadai, dan seinformatif mungkin sesuai yang dibutuhkan. Informasi tersebut tidak boleh melebihi informasi yang sebenarnya dibutuhkan petutur., (Grice, 1991:75) Memberikan jumlah informasi yang tepat yaitu : 
Muhaimin, Implikatur yang Menimbulkan Humor dalam Serial Roku Nin no Okusan oleh Shimura Ken

a. Sumbangan informasi anda harus seinformatif yang dibutuhkan.

b. Sumbangan informasi anda jangan melebihi yang dibutuhkan.

\section{Maksim Kualitas (The Maxim of Quality)}

Maksim Kualitas adalah aturan dalam tuturan dimana peserta tutur dituntut untuk membuat suatu tuturan atau informasi yang terbukti secara fakta, seperti:

a. Jangan mengatakan sesuatu yang anda yakini salah.

b. Jangan mengatakan sesuatu jika anda tidak memiliki bukti yang memadai.

\section{Maksim Hubungan atau Relevansi (The Maxim of Relevance)}

Di dalam maksim hubungan atau relevansi, dinyatakan bahwa agar terjalin kerja sama yang baik antara penutur dan petutur, masing-masing hendaknya dapat memberikan kontribusi yang relevan tentang sesuatu yang sedang dipertuturkan itu (Grice, 1975).

\section{Maksim Cara (The Maxim of Manner)}

Maksim cara memiliki empat sub-maksim, yaitu:

a. Hindarilah ungkapan yang kabur.

b. Hindarilah kata-kata yang berarti ganda (ambigu).

c. Berbicaralah dengan singkat, dan

d. Berbicaralah dengan teratur.

\section{Implikatur}

Implikatur yang dimaksud dalam tulisan ini adalah implikatur percakapan, bukan imlikatur konvensional yang terbentuk dari kata-katanya. Makna implikatur adalah makna yang bukan sebenarnya, atau makna tambahan yang terjadi akibat penutur tidak mematuhi maksim percakapan dengan sengaja karena ada sesuatu yang dimaksud. 


\section{Humor}

Menurut Saifudin dkk. (2019), humor adalah sesuatu, baik verbal maupun nonverbal yang dapat menyebabkan orang tertawa karena situasi yang tidak biasa. Disebut tidak biasa karena pada umumnya humor terjadi karena orang tidak menyangka akan kondisi yang kemudian terjadi. Antara kondisi awal dan kondisi akhir atau selanjutnya, 'dibelokkan' oleh suatu efek kejut 'punch lines' yang menyebabkan orang tertawa karena disadari sebagai sesuatu yang lucu. Dengan demikian dapat dikatakan bahwa humor adalah efek kejut yang menimbulkan kelucuan.

\section{METODE}

Penelitian ini menggunakan metode kualitatif dengan analisis deskriptif. Penelitian ini merupakan studi pragmatik, sehingga dalam menganalisis tuturan-tuturan tidak hanyadarisegibahasa sajamelainkanjugapada konteksnya.

\section{HASIL DAN PEMBAHASAN}

\section{Maksim Kuantitas}

Ken : Rikonshitaika?

Ingin cerai?

Haruna : Shitakuna, anata inakunattara watashi hitoride shinu (2) shikanai.

Tidak ingin, saya lebih baik mati dari pada tidak bersamamu.

\section{Situasi percakapan}

(Shimura Ken, seriRokuninNoOkusan, menit06.27)

Pada sesi sebelumnya Haruna adalah seorang istri yang berani memarahi suaminya, dan selalu menyela apa yang dikatakan oleh suaminya. Sehingga Ken mulai jengkel dan marah dengan kelakuan istrinya yang terus membangkang dan dianggap kurang perhatian tersebut. Ken bertanya dengan maksud untuk mengancam bahwa Ken akan menceraikan istrinya. Seketika istrinya terkejut dan mulai takut, kemudian mulai menyadari bahwa suaminya sedang marah kepadanya. Haruna mencoba untuk meredakan kemarahan istrinya tersebut dengan meminta maaf.

\section{Analisis}

Dilihat dari tuturan (1) "rikonshitaika?" Ken marah dan bertanya pada Haruna 
Muhaimin, Implikatur yang Menimbulkan Humor dalam Serial Roku Nin no Okusan oleh Shimura Ken

apakah ingin bercerai dengannya. Jawaban dari pertanyaan ini seharusnya "iya ingin" atau "tidak tidak ingin" "tanpa harus mengungkapkan alasan. Karena tidak ada kata Tanya "kenapa" yang harus mengungkapkan alasan. Tetapi Haruna menjawab pertanyaan dengan disertai alasan "anata inakunattara watashi hitoride shinu shikanai" Yang artinya "saya lebih baik mati dari pada tidak bersamamu". Di situlah letak informasi yang berlebih. Tuturan (2) "shitakunai, anata inakunattara watashi hitoride shinu shikanai "memiliki makna implikasi bahwa Haruna ingin menyampaikan maksud secara tidak langsung dan meminta maaf. Meskipun tidak ditanyakan alasannya Haruna sengaja memberikan alasan tersebut karena haruna mulai menyadari kesalahannya. Dengan menyatakan rasa sayang tersebut Haruna berharap dapat meluluhkan perasaan suaminya yang sedang marah dan mengancamnya dengan pertanyan tersebut. Haruna berharap mendapatkan maaf dari suaminya,

Hal tersebut menandakan bahwa pelangaran prinsip kerja sama maksim kuantitas berupa berlebihnya informasi yang disampaikan oleh Haruna dan terdapat implikatur percakapan tersebut dapat menimbulkan efek humor, informasi berlebih yang di sampaikan Haruna menjadikan posisi Haruna menjadi lemah dan kontras sekali dengan sikap-sikap sebelumnya terhadap suaminya. Pada awalnya penonton mengira bahwa Haruna adalah istri yang sangat galak dan pemberani, tetapi dengan informasi yang berlebih tersebut justru menandakan bahwa Haruna bukanlah seperti apa yang dibayangkan oleh penonton pada sesi sebelumnya. Implikatur percakapan yang ada dapat menimbulkan efek humor pada penonton yang ditandai dengan tawa penonton sesaat setelah tuturan tersebut diujarkan. Artinya penulis naskah berhasil menyampaikan implikatur percakapan yang dapat menimbulkan efek humor melalui dialog tersebut kepada penonton sebagai mitra tuturnya.

\section{Maksim Kualitas}

Ken : Tadaima

Saya pulang

Haruna : Kenchanokaeri.

Selamat datang Ken

Ken : Hai,...ee, nandeoma?kodomokaomae? kodomokaore?

Ya...ee, kenapa kamu? apa kamu anak-anak? apa aku anakanak?

(Shimura Ken, seriRokuninNo Okusan, menit06.57) 


\section{Situasi percakapan}

Ken menganggap bahwa Haruna tidak tahu tata karena dan kurang perhatian. Ken mencoba mengajarkan istrinya dengan membuat simulasi tentang beberapa hal yang harus dilakukan sejak suaminya baru pulang dari bekerja. Pada contoh yang pertama masih gagal. Kemudian dengan contoh yang kedua dan berikutnya. Ken membuka pintu dan mengucapkan salam. Meskipun jawaban salamnya sudah benar tetapi Haruna memanggil suaminya dengan panggilan "Ken chan" di mana panggilan tersebut adalah panggilan yang umumnya digunakan untuk mememanggil anak-anak. Ken balik bertanya kepada Haruna kenapa memanggilnya dengan pangggilan seperti itu.

\section{Analisis}

Tuturan nomor (2) "Ken chan okaeri” bisa dikatakan melanggar prinsip kerjasama maksim Kualitas yaitu peserta tutur diharapkan untuk tidak mengatakan sesuatu yang tidak benar dan faktanya kurang meyakinkan. "Tadaima” merupkan ucapan salam yang diucapkan ketika orang Jepang pulang kerumah. Tuturan (2) "ken chan okaeri" merupakan jawaban dari Haruna untuk menjawab salam dari ken. Kata "chan" dalam bahasa Jepang memiliki fungsi sebagai panggilan yang digunakan untuk anak-anak atau kakek nenek. Tuturan tersebut didukung dengan tuturan (3) "hai,...ee, nande omae? kodomoka omae? kodomo ka ore?" Yang menyatakan bahwa ken menolak dipanggil dengan sebutan "ken chan" dan kembali bertanya pada Haruna "apakah Haruna menganggap dirinya seperti anak-anak."

Tuturan tersebut mempunyai implikasi bahwa istri Ken sengaja menuturkan tuturan yang tidak benar dan tidak sesuai dengan fakta sebenarnya karena Haruna merasa jengkel kepada suaminya. Secara tidak langsung Haruna ingin mengatakan bahwa Ken seperti anak-anak dengan menyebutnya dengan sapaan "Ken chan" dan sikap tersebut dianggap merendahkan posisi Ken sebagai suami Haruna. Hal tersebut dianggap lucu oleh penonton dan membuat penonton tertawa. Penonton menilai bahwa implikatur percakapan yang ada pada tuturan Haruna tersebut yang memiliki maksud untuk mengejek secara tidak langsung dengan memanggil suaminya dengan kata "Ken chan" tersebut menggambarkan bahwa Suaminya yang sudah dewasa disamakan dengan 
Muhaimin, Implikatur yang Menimbulkan Humor dalam Serial Roku Nin no Okusan oleh Shimura Ken

anak kecil yang harus dipanggil dengan sebutan "chan" sehingga tuturan tersebut membuat Ken semakin kesal dan terdengar sebagai sesuatu yang lucu oleh penonton. Fakta yang tidak sesuai tersebut membuat posisi Ken menjadi lemah dan secara tidak langsung Haruna merendahkan posisi suaminya, yang seolah-olah dia tidak tahu bahwa tuturan tersebut adalah salah. Implikatur percakapan yang ada dapat menimbulkan efek humor pada penonton yang ditandai dengan tawa penonton sesaat setelah tuturan tersebut diujarkan. Artinya penulis naskah berhasil menyampaikan implikatur percakapan yang dapat menimbulkan efek humor melalui dialog tersebut kepada penonton sebagai mitra tuturnya.

\section{Maksim Relevansi}

Rie : Otoko, imoto, kodomo, hitorigurai iikana

Anak laki, anak perempuan, anak, seorang anak lagi

bolehlah

Ken : Mo, oremo hora, toshidakarana

Saya sudah tua gini kok

(Shimura Ken, seriRokuninNoOkusan, menit 12:24)

\section{Situasi percakapan}

Setelah kedua anak mereka berselisih ingin mempunyai adik. Ken tidak menanggapi apa yang diinginkan oleh anaknya tersebut dan menyuruh anak-anak nya untuk tidur, di ruang makan hanya ada Ken dan Rie. Rie mencoba menggoda suaminya tentang apa yang diinginkan oleh kedua anaknya, yaitu memiliki adik. Dengan nada yang manja menggoda Rie mencoba merayu Ken untuk menuruti kemauan anaknya itu. Tetapi Ken terus menghindari pembicaraan itu.

\section{Analisis}

Tuturan (1) “otoko, imoto, kodomo, hitorigurai iikana” bisa dikatakan melanggar prinsip kerjasama maksim cara sub maksim (b) yaitu Hindari kata kata yang berarti ganda atau ambigu. Apa yang di tuturkan oleh Rie tidak teratur sehingga maksud dari tuturan itu tidak dapat tersampaikan dengan baik. Rie mengatakan "anak laki-laki" 
kemudian "anak perempuan" kemudian "anak" dan terahir mengatakan "seorang anak lagi boleh lah" apa yang ingin di bahas oleh Rie dalam tuturan tersebut tidak spesifik, bermakna ambigu dan membingungkan, sehingga tuturan tersebut bisa dikatakan melanggar prinsip kerjasama. implikatur percakapan pada tuturan tersebut bahwa Rie sengaja tidak mengungkapkan keinginnannya secara langsung karena malu kepada Ken.

Tuturan (2) bisa dikatakan melanggar Prinsip Kerjasama Maksim Hubungan atau Relevansi yaitu agar terjadi kerjasama yang baik antara penutur dan mitra tutur masing masing hendaknya dapat memberikan kontribusi yang relevan tentang sesuatu yang di pertuturkan itu. Ken menyatakan bahwa umurnya sudah tua padahal dari tuturan sebelumnya tidak ada yang menanyakan atau membahas tentang umur. Tuturan Ken yang tidak relevan ini memiliki alasan tersendiri, oleh karena itu tuturan Ken tersebut memiliki makna implikatur percakapan bahwa Ken menolak secara tidak langsung terhadap tuturan Rie yang ambigu. Ken mengerti maksud Rie bahwa Rie ingin mengajaknya berhubungan intim. Walaupun dengan tuturan yang tidak langsung. Ajakan tersebut ditolak oleh Ken dengan mengatakan bahwa dia sudah tua. Ken ingin memberi alasan tentang resiko kedepan jika memiliki anak pada usia tua. wacana kepada Rie bahwa semakin tua umur sebuah pasangan maka hasrat untuk melakukan itu semakin berkurang. Apabila mempunyai anak pada usia tua untuk ke depannya kebutuhan semakin meningkat dan ekonomi melemah dikarenakan masa tua bukanlah masa produktif lagi untuk bekerja. Implikatur percakapan yang ada dapat menimbulkan efek humor pada penonton yang ditandai dengan tawa penonton sesaat setelah tuturan tersebut diujarkan. Artinya penulis naskah berhasil menyampaikan implikatur percakapan yang dapat menimbulkan efek humor melalui dialog tersebut kepada penonton sebagai mitra tuturnya.

\section{Maksim cara}

Ken : Naniyatteirukore?

Apa yang kamu lakukan?

Haruna : "Naniyatteiru wakaru "deshou sentakumono wo tatandeiru "Apa yang kamu lakukan"sudah tau sedang melipat

Ken : Ore wakaruyo,omae

Aku sudah tau lah. 
Muhaimin, Implikatur yang Menimbulkan Humor dalam Serial Roku Nin no Okusan oleh Shimura Ken

(Shimura Ken, seriRokuninNoOkusan, menit06.05)

\section{Situasi percakapan}

Ken dan Haruna adalah seorang suami istri yang tinggal di rumah sederhana. Ken pulang kerumah Sambil menenteng tas kerjanya dan membuka pintu, kemudian mengucapkan salam. Istrinya (Haruna) keluar dari ruang belakang dan membalas salam dari suaminya sambil membawa setumpuk jemuran dan langsung melipatnya di ruang tamu. Dengan rasa kesal Ken bertanya kepada Haruna tentang apa yang sedang dilakukan.

\section{Analisis}

Tuturan (1) "Nani yatteiru kore?" melanggar prinsip kerjasama yaitu maksim cara sub maksim (b) hindari ungkapan yang bermakna tidak jelas atau kabur. (1) "Nani yatteiru kore" adalah tuturan yang tidak jelas diperkuat dengan tuturan no (2) "naniyatteiru" wakaru deshou sentakumono wo tatandeiru" yang menyatakan bahwa Haruna menyangkal pertanyaan Ken tersebut dengan mengulangi kata yang diucapkan oleh Ken, kemudian Haruna menyuruh ken untuk melihat dengan mata kepalanya sendiri aktivitas apa yang sedang dilakukan oleh Haruna.

Tuturan (2) "naniyatteiru” wakaru deshou sentakumono wo tatandeiru” bisa dikatakan melanggar prinsip kerjasama maksim kuantitas sub maksim (a) sumbangan informasi anda harus seinformatif yang di butuhkan. Pada waktu Ken bertanya pada Haruna dengan tuturan (1) "Nani yatteiru kore?" dijawab dengan tuturan tuturan (2) "naniyatteiru" wakaru deshou sentakumono wo tatandeiru" informasi yang ditanyakan oleh Ken tidak dijawab dengan jawaban yang sesuai dengan pertanyaan. Haruna mengulang pertanyaan Ken dan memberikan statemen yang menjengkelkan. Oleh karena itu tuturan tersebut tidak memberikan sumbangan informasi yang seinformatif yang dibutuhkan. Tuturan (2) "naniyatteiru” wakaru deshou sentakumono wo tatandeiru” mempunya makna implikasi bahwa Haruna ingin mengetahui lebih dalam maksud dari pertanyaan suaminya tersebut. Haruna menunjukkan sikap jengkel, 
atau tidak suka terhadap pertanyaan suaminya yang seharusnya tanpa bertanya saminya sudah tahu aktifitas yang sedang dilakukan istrinya karena bisa melihat secara langsung. Haruna merasa harus menyelesaikan pekerjaannya karena kesibukkannya sebagai ibu rumah tangga, sedangkan suaminya merasa kurang diperhatikan oleh istrinya karena pada waktu pulang tidak disambut dengan sesuatu hal yang menenangkan. Terdapat dua perasaan yang berbeda dalam dialog tersebut tetapi tidak disampaikan secara langsung.

Pada tuturan (3) "ore wakaruyo, omae" yang artinya "aku sudah tau lah" dari tuturan tersebut bisa diinterpretasikan bahwa Ken mengetahui sebuah informasi. Karena diucapkan dengan nada tinggi terdapat kesan tidak senang, jengkel, atau menyangkal dalam tuturan tersebut. Padahal pada paparan tuturan (1) sebelumnya Ken bertanya kepada Haruna. Dan dijawab oleh Haruna, tetapi pada tuturan (3) seolah-olah Ken sudah tahu jawaban dari tuturan (1) sehingga bisa dikatakan tuturan (1) bukan sebuah tuturan pertanyaan, mekipun secara struktur merupakan kalimat tanya. Oleh karena itu tuturan (3) "ore wakaruyo,omae" bisa dikatakan melanggar prinsip kerjasama maksim cara sub maksim (a) Hindari ungkapan yang kabur atau tidak jelas. Tuturan tersebut mempunyai arti bahwa Ken mengetahui sesuatu informasi, tetapi pada tuturan sebelumnya tidak ada pertanyaan yang mengharuskan Ken untuk menjawab bahwa dia mengetahui sebuah informasi lebih di pertegas lagi pada tuturan (1) "Nani yatteiru kore?" Bahwa sebenarnya Ken bertanya, tetapi pada tuturan (3) "ore wakaruyo, omae" Seolah-olah ken menjawab pertanyaannya sendiri. Tuturan itulah yang dikatakan mempunyai ungkapan yang kabur atau tidak jelas. Tuturan tersebut mempunyai makna implikasi bahwa Ken ingin menegaskan sesuatu yaitu maksud tuturan (1) belum tersampaikan meskipun istrinya mengelak dan jengkel serta tahu tuturan Ken tersebut bermakna kabur atau tidak jelas. Ken ingin mempertegasnya dengan tuturan (3) Maksud yang belum disampaikan itu adalah Ken ingin diperhatikan pada saat pulang kerja. Ken sebagai suami yang sehari-hari mencari nafkah untuk istrinya ingin dihormati dengan cara yang benar.

Pada tuturan (3) “ore wakaruyo, omae”(audience laugh) penonton tertawa mendengar tuturan tersebut. Penonton menertawakan posisi Ken yang jengkel kepada istrinya tersebut menandakan bahwa tuturan tersebut mengandung makna lucu. 
Muhaimin, Implikatur yang Menimbulkan Humor dalam Serial Roku Nin no Okusan oleh Shimura Ken

Implikatur percakapan yang ada dapat menimbulkan efek humor pada penonton yang ditandai dengan tawa penonton sesaat setelah tuturan tersebut diujarkan. Artinya penulis naskah berhasil menyampaikan implikatur percakapan yang dapat menimbulkan efek humor melalui dialog tersebut kepada penonton sebagai mitra tuturnya.

\section{SIMPULAN}

Implikatur percakapan yang dapat memberikan efek humor kepada penonton dalam acara komedi Jepang "shimura Ken" seri rokunin no okusan. Terdapat pelanggaran prinsip kerjasama percakapan yaitu: Permintaan maaf, ancaman, penyangkalan, mengejek, menegur, menegaskan sesuatu, memerintah, mengalihkan pembicaraan, menakut-nakuti, mempengaruhi, dan penolakan.

Implikatur percakapan yang dapat menimbulkan efek humor kepada penonton adalah: (1) Implikatur yang ada merupakan gambaran situasi yang terjadi tidak sesuai dengan apa yang dibayangkan sebelumnya. (2) implikatur yang ada berpotensi, melemahkan, menganiaya, meminggirkan, menyusahkan, Memojokkan. (3) Implikatur yang ada merupakan gambaran kondisi yang tidak diinginkan, penolakan, ketidaksetujuan, keterpaksaan, kemarahan dan perlawanan. Implikatur digunakan sebagai sarana penunjang terciptanya humor oleh penutur kepada mitra tutur (penonton) yang ditandai dengan tawa penonton, sehingga tujuan dari acara yang bertemakan tentang humor dapat tersampaikan yaitu sebagai hiburan bagi masyarakat.

\section{REFERENSI}

Andyka Miftakhul Farild. (2012). Implikatur-implikatur percakapan dalam wacana humor Gusdur. Skripsi Sarjana Sastra Indonesia Universitas Sebelas Maret Surakarta: tidak diterbitkan.

Ariefandi, F. (2018). Ilokusi yang memberikan efek humor kepada pembaca dalam manga Azumanga Daioh. Lite:Jurnal Bahasa, Sastra, dan Budaya 14 (2), 118 138.

Grice, H.P. (1975). Logic and Conversation. Dalam Syntax and Semantics.

Kimie, O. (2013). An Examination for Styles of Japanese Humor: Japan's Funniest Story.

Leech, G. (1993). Prinsip-Prinsip Pragmatik. (Terj) M. D. D. Oka. Jakarta: Universitas Indonesia. 
Levinson, Stephen C. (1983) Pragmatics. Great Britain: Cambridge University Press. Nadar, F. X. (2009). Pragmatik dan Penelitian Pragmatik. Yogyakarta: Graha Ilmu.

Nawa, A. (2013). Differences of Sense of Humor Between Cultures; An Analysis of Two Comedy Acts in Japan and the US. Aichi, Jepang: Thesis Aichi Shukutoku University.

Saifudin, A., Risagarniwa, Y.Y., Citraresmana, E., Sidiq, I.I. (2019). Pengembangan Alat Analisis Humor dalam Komik Jepang. Japanese Research on Linguistics, Literature, and Culture 1 (2), 129-143.

Saifudin, A. (2018). Konteks dalam Studi Linguistik Pragmatik. Lite: Jurnal Bahasa, Sastra, dan Budaya 14 (2), 108-117.

Saifudin, A., Risagarniwa, Y.Y., Citraresmana, E. (2017). Developing a Semiotic Analysis Tool of Humor in Manga: A Pilot Study of Cognitive and Cultural Representation in Humorous Comic. 6 th Global Conference on Business and Social Sciences on "Contemporary Issues in Business and Social Sciences Research" (CIBSSR - 2017)

Saifudin, A. (2017). Penggunaan Manga Humor dalam Pembelajaran Bahasa dan Penelitian Bahasa Jepang. JAPANEDU: Jurnal Pendidikan dan Pengajaran Bahasa Jepang 2 (2), 99-113.

Saifudin, A. (2005). Faktor Sosial Budaya dan Kesopanan Orang Jepang dalam Pengungkapan Tindak Tutur Terima Kasih pada Skenario Drama Televisi Beautiful Life Karya Kitagawa Eriko. Thesis. Program Pascasarjana KWJ UI: Jakarta.

Setiawan, A. (1990). Teori Humor. Jakarta: Majalah Astaga, No. 3 Th. III, hal.34-35.

Yamazaki. (2010, March 3). Conversational Implicature in Stand-up Comedies.

Tri Astuti. (2011). Analisis Implikatur Percakapan Tokoh Chieko dalam Novel Koto Karya Yasunari Kawabata. Skripsi Sarjana Sastra FIB Universitas Dian Nuswantoro Semarang: Tidak diterbitkan. 